\title{
Las supuestas Tabulae Lusoriae de los foros de Roma y Sufetula (Túnez)
}

Antonio TEJERA GASPAR*

\section{Resumen}

En este artículo planteo la posibilidad de que algunas tabulae lusoriae de los fora de las ciudades romanas de Sufetula (Túnez) y Roma, puedan tener una explicación distinta a la que tradicionalmente se le ha atribuido.

Palabras clave: Tabulae lusoriae. Foro. Sufetula. Roma.

\section{Summary}

In this article I argue about some tabulae lusoriae from the fora, on the roman cities of Sufetula (Tunisia) and Rome, and I propose that these motive engraved can be explained of other form as have been traditionally explained.

Keywords: Tabulae lusoriae. Foro. Sufetula. Roma.

Para este homenaje dedicado al profesor Bendala, me ha parecido oportuno referirme a las supuestas tabulae lusoriae existentes en los fora de Roma, y en el de la ciudad tunecina de Sufetula-Sbeitla, en Túnez. Con estas notas solo pretendo dar continuidad a un trabajo suyo que fue publicado en el $n^{\circ} 4$ de la revista Habis, el año 1973, en donde nuestro homenajeado estudiaba, de manera detallada, una serie de figuras grabadas con estos motivos en las losas situadas en el suelo del scaenae frons del Teatro de Italica $^{1}$.
En un proyecto de investigación de arqueoastronomía del que formábamos parte, dirigido por Juan Antonio Belmonte Avilés ${ }^{2}$-investigador del Instituto de Astrofísica de Canarias-, tuvimos la oportunidad de localizar una serie de motivos circuliformes -de unos $40 \mathrm{cms}$ de diámetro- que se hallan grabados en las losas del suelo de los foros de las ciudades romanas tunecinas de Thugga $a^{3}$ y Sufetula (Sbeitla), que por su semejanza con los de Italica, pensamos que podían ser interpretados del mismo modo que aquéllos, como tablas de juego. Los de Sufetula son dos círculos radiados,
* Catedrático de Arqueología. Facultad de Geografía e Historia. Universidad de La Laguna, Tenerife. atejera@ull.es.

1 M. Bendala Galán. "Tablas de juego en Itálica", Habis $\mathrm{n}^{\circ}$ 4, 1973, pp. 263-272. Ver asimismo Antonio Caballo Rufino, Jesús Marín Fatuarte y José M. Rodríguez Hidalgo. Itálica Arqueológica. Ediciones especiales, $\mathrm{n}^{\circ} 25$. Universidad de Sevilla, Junta de Andalucía, Fundación El Monte. Sevilla 2002:95.
2 J.A. Belmonte, A. Tejera A, M.A. Perera and R. Marrero. "On the orientation of pre-Islamic temples of North-west Africa: a reappraisal New data in Africa Proconsularis." Mediterranean Archaeology and Archaeometry 6, 3 (2007), pp. 77-85.

3 Este círculo radiado se encuentra en la plaza de los vientos, en el foro de la ciudad, frente al templo capitolino. Mide $44 \times 40 \mathrm{cms}$, pero del que no fue posible tomar ninguna orientación. 
en los que se pueden observar las líneas principales que dividen el motivo y que siguen una orientación N-S, cortada por otra que lo hace en dirección E-W, completada con las líneas restantes, hasta conformar los motivos radiados a los que nos referimos. (Fig. 1 y 4 ).

En una visita al foro de Roma, en septiembre de 2010, pude observar asimismo la existencia de una figura radiada, similar a las de Túnez -aunque en apariencia de mayor tamaño-, de la que solo poseo las fotos que acompañan a estas notas, pero de la que desconozco sus dimensiones y cualquiera otra característica. Se halla en un espacio acotado en la plaza entre la vía sacra y la calle de la Basílica Iulia, en donde se encuentra la columna Foca, erigida delante de los Rostra, y dedicada al emperador de Oriente el 1 de agosto del 608, considerada además como la última adición hecha en el Foro de Roma. ${ }^{4}$ Se trata de una columna corintia que mide 13,6 $\mathrm{m}$ de altura, desde su pedestal cúbico de mármol blanco, y para la que en su cons-

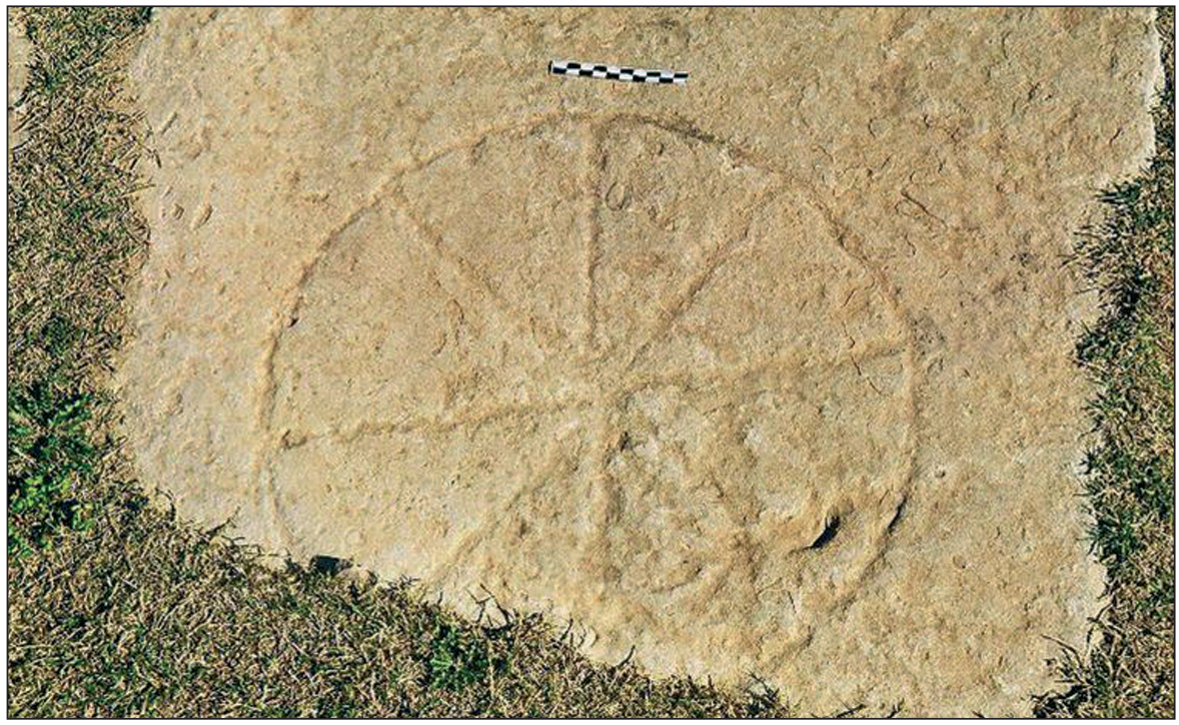

Figura 1. Circulo radiado, grabado en una losa del foro de Sufetula-Sbeitla (Túnez).

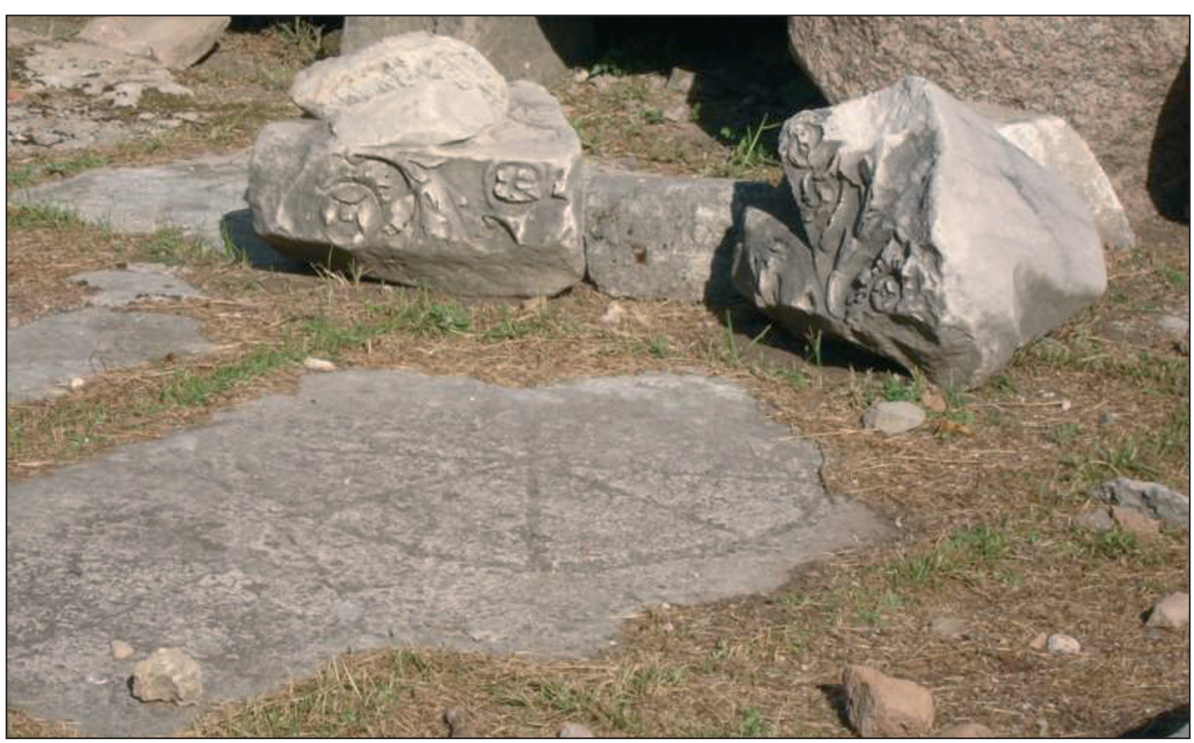

Figura 2. Circulo radiado en el foro de Roma, cerca de la columna foca.

4 Lexicon topographicum urbis Romae, coordinado por Eva Margareta Steinby y publicada por la Editorial Roma, Edicioni Quasar, 1993-1995. T.I, p. 307. En esta obra no he encontrado ninguna referencia gráfica al motivo al que nos referimos en el texto. Agradezco al profesor J.A. Delgado, Titular de Historia Antigua de la Universidad de La Laguna, las indicaciones bibliográficas que me ha hecho. 
trucción se utilizaron elementos arquitectónicos del siglo II. (Fis. 2 y 3 ).

En la bibliografía que he consultado, todos los autores interpretan siempre estos motivos como representaciones de juegos. Sin embargo, por la ubicación y características de los recogidos aquí, así como por el lugar en el que se hallan emplazados, me parece que podrían responder a otra finalidad, y por tanto valorados de modo muy diferente a como lo han sido tradicionalmente, ya que no se trata, como los del Teatro de Italica, ubicados en un espacio lúdico, sino en el lugar más emblemático y de mayor dignidad de una ciudad romana. Para plantear nuestra propuesta, hemos consultado Los diez libros de Arquitectura de Vitruvio, en concreto el capítulo VI del libro I, que el autor dedica al modo en el que habría de procederse en el momento de la fundación de una

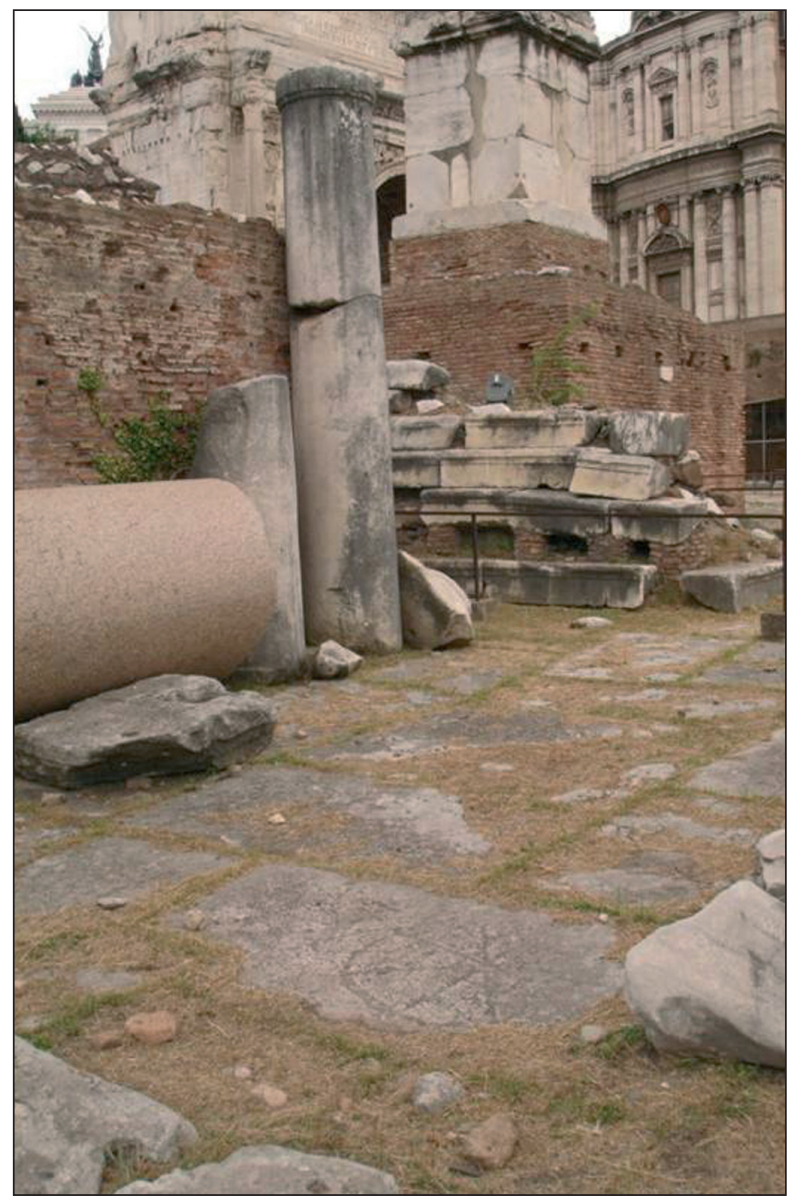

Figura 3. Circulo radiado en el foro de Roma. La columna foca y el arco de septimio severo.

5 Vitruvio Polión, Marco Lucio. Los diez libros de Arquitectura. Introducción de Delfín Rodríguez Ruiz. Versión española de José Luis Oliver Domingo. Alianza ciudad, y que figura encabezado con el epígrafe, "División de las obras en el interior de las murallas." ${ }^{5}$ En él se alude de manera expresa al problema de la procedencia de los vientos, a partir de los que se debe orientar la planimetría urbana y sobre la que ha de establecerse asimismo la modulación de la ciudad y sus partes. Para ello, nuestro autor determina que después de conocer las zonas y los orígenes de los vientos, se colocará "un cuadrante de mármol en medio de la ciudad, perfectamente nivelado, o bien alisaremos un lugar y lo nivelaremos de modo que sea preciso el cuadrante; sobre su parte central, en el medio se colocará un gnomon de bronce, como indicador de la sombra." ${ }^{6} \mathrm{Y}$ "Desde estos dos puntos, con el compás trazaremos una figura en forma de aspa y por el punto donde se corten las dos líneas del aspa, exactamente por ese punto, debe trazarse

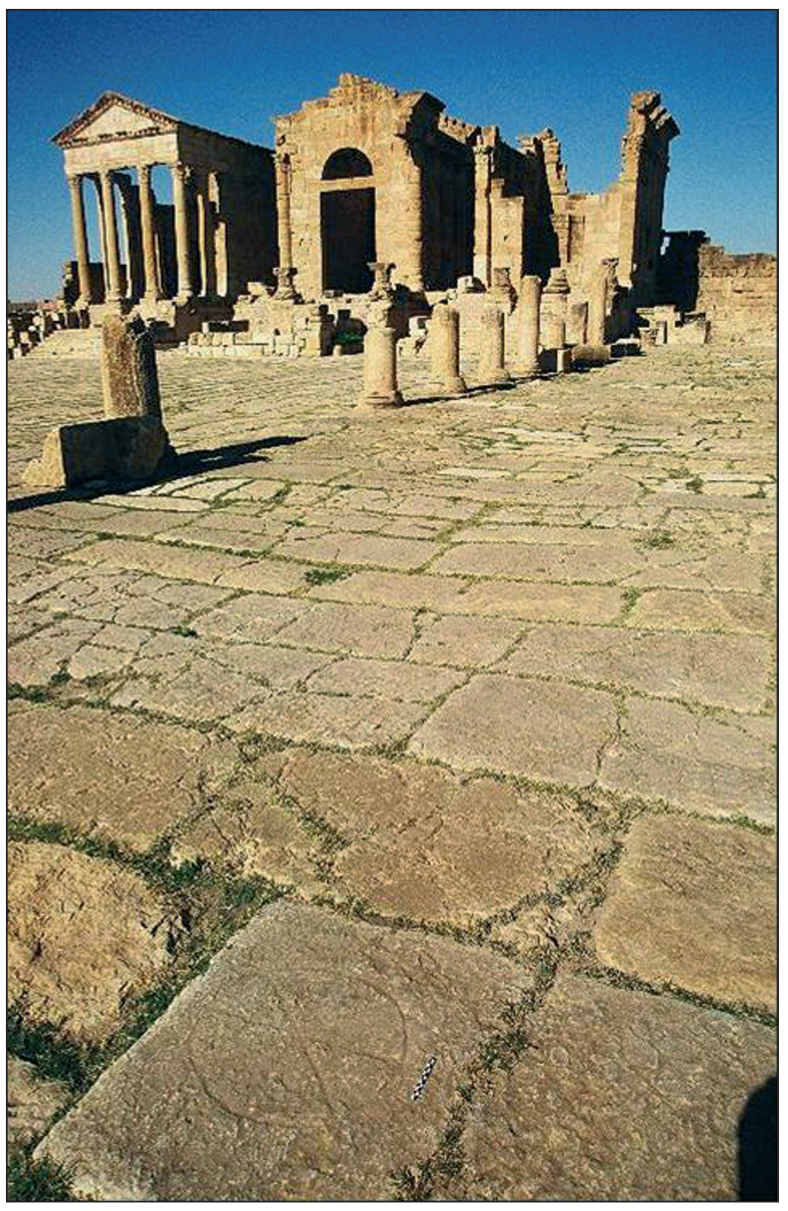

Figura 4. Circulo radiado, grabado en una losa del foro de Sufetula-Sbeitla (Túnez). Al fondo, los tres templos del capitolio.

Forma. Alianza Universidad, 2002, p. 81.

6 Ibidem, p. 83. 
una línea hasta el extremo, y así quedarán señaladas tanto la parte o región meridional como la septentrional. A continuación, debe tomarse la decimosexta pare de la circunferencia y debe situarse el centro de la línea meridional donde corta la circunferencia; desde allí señalaremos a derecha y a izquierda -en la misma circunferencia- dos puntos: el de la parte meridional y el de la septentrional. A continuación, desde estos cuatro puntos se trazarán unas líneas por el centro donde se juntan los dos trazos del aspa, desde un extremo hasta el otro extremo. Así, la indicación del austro y del septentrión ocuparán una octava parte cada uno. Las partes restantes, tres a la derecha y tres a la izquierda, deben distribuirse por igual en la totalidad de la circunferencia, con el fin de que queden plasmados en el gráfico unos espacios iguales para los ocho vientos. Siguiendo los ángulos, entre las dos zonas de los vientos, se alinearán los trazados de las plazas y de las calles. Siguiendo esta estructuración descrita, los vientos perjudiciales quedarán excluidos de las viviendas y de las calles. Efectivamente, cuando las plazas se dispongan directamente frente a la dirección de los vientos, la intensidad del viento continuo se extenderá desde el cielo abierto con fuerte violencia y se potenciará al estar encerrado en las angostas callejuelas. Por ello, es necesario orientar los barrios atendiendo a las direcciones de los vientos, con el fin de que al llegar a las esquinas de los bloques de casas se debiliten y, repelidos, terminen disipándose."’

Como complemento a lo expresado por Vitruvio sobre el modo en el que se han de trazar las calles de una ciudad romana, me ha parecido pertinente señalar asimismo la referencia contenida en la comedia del griego Aristófanes (445 a. C. 385 a. C.), en su obra "Las Aves", con la que ganó el segundo premio en las Grandes Dionisias del año 414 a. C. En uno de los pasajes de la obra, y en forma dialogada, el comediógrafo se refiere al famoso astrónomo, matemático, geómetra e ingeniero griego Metón, a quien reclama para que diseñe las calles de una ciudad imaginaria, y al que podría compararse asimismo con el

7 Vitruvio Polión, Marco Lucio. Los diez libros de Arquitectura. Introducción de Delfín Rodríguez Ruiz. Versión española de José Luis Oliver Domingo. Alianza Forma. Alianza Universidad, 2002, p. 83-84.

8 Aristófanes. Las Aves, Edición de Francisco Rodríguez otro arquitecto griego, Hipódamos, del que conocemos unas pocas pincelada que nos fueron legadas por Aristóteles, por quien sabemos que fue el gran arquitecto y diseñador de la ciudad de Mileto, en Asia Menor, según lo recoge el filósofo estagirita en el libro II, cap. V, de su Política, y en donde nos dice que era hijo de Eurifón, y el inventor de la división de las ciudades en calles, que aplicó también al puerto del Pireo.

METÓN. (Viste el coturno trágico. Lleva una escuadra, un compás, un cordel) Vengo a vuestra ciudad...

PISTETERO. ¡Otra calamidad! ¿A qué? ¿Qué te propones? ¿Cuál es la intención, cuál es el coturno...de tu viaje?

METÓN. Quiero parcelar el aire y dividirlo en yugadas.

PISTETERO. ¡ Por los dioses! ¿Y quién eres tú?

METÓN. ¿Qué quien soy? Metón, a quien conoce Grecia... ¡Y hasta Colono!

PISTETERO. Pero, dime ¿qué es eso?

METÓN. Cordeles para medir el aire. El aire, sábelo bien, tiene la forma de un horno, más o menos. Pongo encima este cordel curvado, aplico el compás..., ¿comprendes?

PISTETERO. No comprendo.

METÓN. Tomaré las medidas con un cordel puesto en línea recta, inscribiendo el círculo en un cuadrado; en medio estará la plaza, a la que llevarán vías directas y, como de una estrella, pues será circular, por todas partes saldrán de ella los rayos, espléndidas calles rectas 8 .

A la vista de lo referenciado, creo -con todas las reservas que el caso merece- que las dos figuras radiadas del foro de Sufetula, divididas en ocho secciones, pudiera tratarse en realidad de la figuración del lugar en el que se hallaba ubicado el mundus ${ }^{9}$, con el que se señalaba el emplazamiento fundacional de la ciudad romana, y desde la que habría de hacerse su primera modulación y, en su caso, la de las futuras ampliaciones que fue-

Adrados. Cátedra. Letras Universales, 2009 pp. 222-223.

9 Joseph Rykwert. La idea de ciudad. Ediciones Sígueme. Salamanca, 2002, p.74. 
ran necesarias, de manera que el espacio urbano mantuviese siempre una trama geométrica bien ordenada, partiendo de lo primeramente establecido en el Foro, espacio considerado como centro neurálgico de la ciudad. En este sentido, me ha parecido especialmente relevante la traducción que se hace de este mismo pasaje en la edición facsimilar de la obra de Vitruvio, impresa el año $1787^{10}$, en donde en el mismo capítulo VI, 44, que el autor titula "De la recta distribución y situación de los edificios de muros adentros," un tanto diferente al de la edición arriba señalada, cuando alude a la manera con la que se ha de proceder para la planificación de la ciudad. Joseph Ortíz lo ha traducido por "ó bien pavimentese un lugar allí mismo, y allanese á nivel y regla, de modo que no se necesite pedestal alguno ${ }^{11}$ ", de lo que parece deducirse que el lugar elegido para modular la ciudad debía de estar especialmente señalado. Y es esta la función que creemos se le puede atribuir, al menos a uno de los citados círculos de Sufetula, en los que su orientación coincide preci- samente con los ejes del cardo y del decumanus maximus, y que según las mediciones y los cálculos realizados por el Dr. Belmonte Avilés, el cardo podría estar orientado hacia la salida de la estrella Sirius, la más brillante del cielo, con la que pudo haberse hecho coincidir el sitio elegido para la fundación de la ciudad. (Fig. 4).

Nada de lo dicho se ha podido comprobar, en cambio, en el ejemplo citado del foro de Roma, que debe quedar para un análisis de conjunto de este tipo de figuras, si fuera posible documentarlas en otros tantos foros de las ciudades romanas, o de las que se hallaren emplazados en sitios destacados y singulares de la trama urbana, a partir de los que acaso se podría corroborar lo planteado en estas pocas notas, con las que he querido contribuir al merecido homenaje del profesor Bendala, tratando de llamar la atención sobre un tema que le es de mucho agrado, y dejando a los especialistas el estudio en profundidad de estos aspectos por si pudieran tener algún interés en futuras investigaciones. (Figs. 5 y 6).

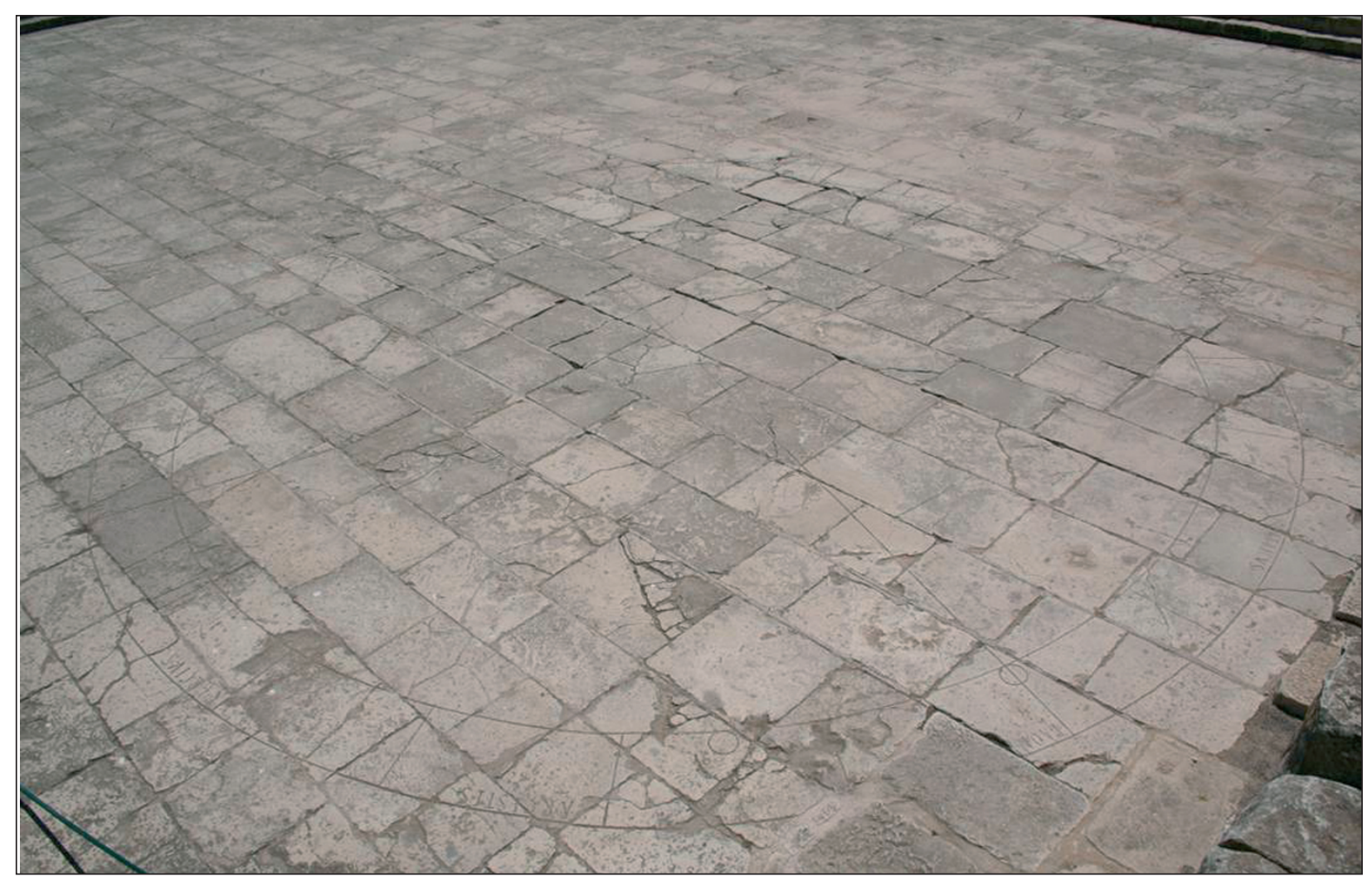

Figura 5. La plaza de los vientos de la ciudad romana de Thugga (Túnez).

10 Vitrubio, Marco. Los Diez libros de Arquitectura. Facsímil de la edición de 1787. Imprenta Real. Madrid. Traducidos del latín y comentados por Don Joseph Ortíz y Sanz,
Presbítero. Biblioteca Altafulla, Barcelona. 1993. Capítulo VI, 4. P. 21.

11 Ibidem, las negritas son nuestras. 


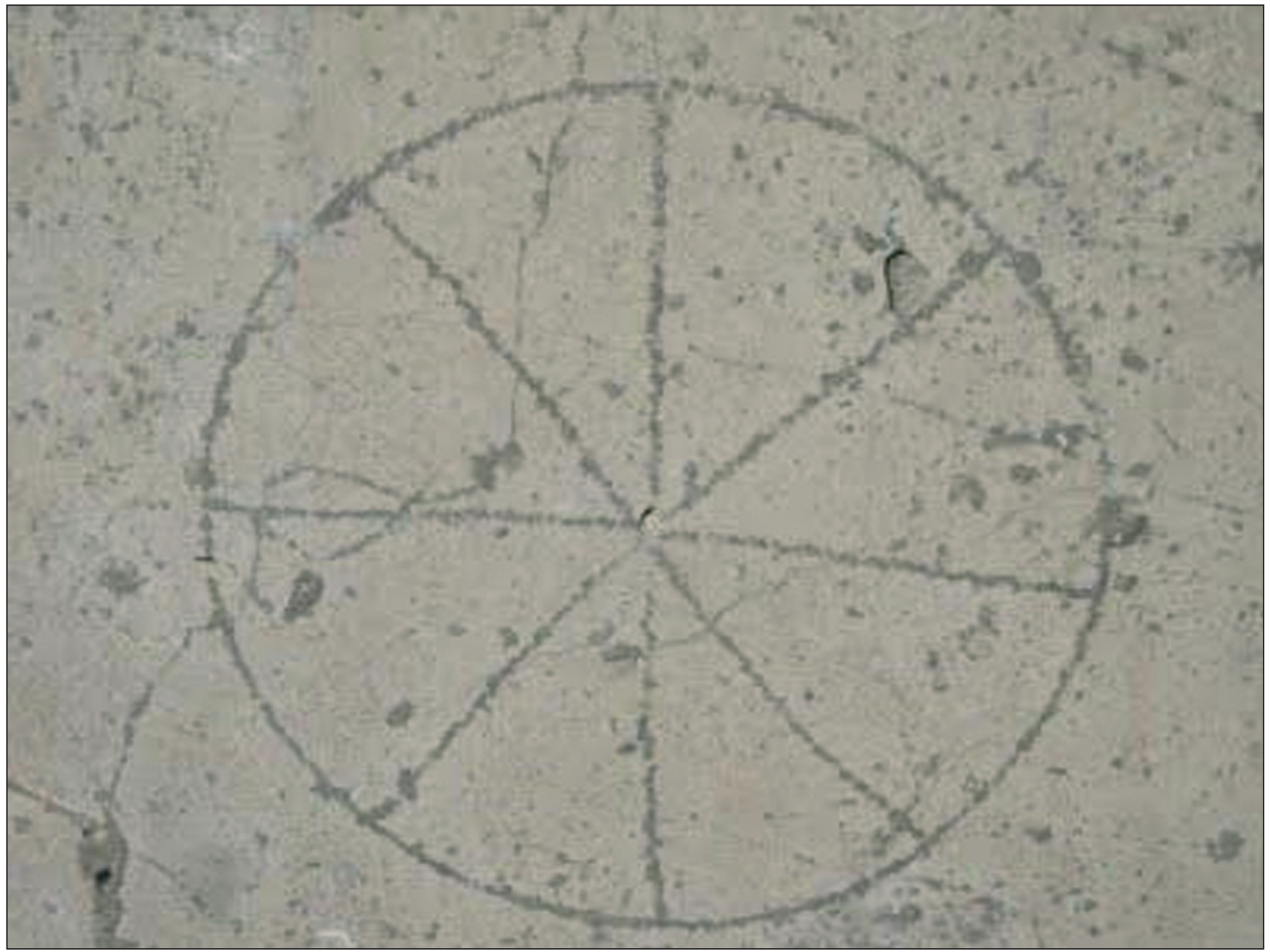

Figura 6. Circulo radiado en la plaza de los vientos de la ciudad romana de Thugga (Túnez).

\section{Bibliografía}

ARISTÓFANES (2009): Las Aves, Edición de Francisco Rodríguez Adrados. Cátedra. Letras Universales.

BENDALA GALÁN, M (1973): "Tablas de juego en Itálica", Habis n ${ }^{\circ}$ 4, pp. 263-272.

CABALLO RUFINO, Antonio, Marín Fatuarte, Jesús y Rodríguez Hidalgo, José M. (2002): Itálica Arqueológica. Ediciones especiales, $\mathrm{n}^{0} 25$. Universidad de Sevilla, Junta de Andalucía, Fundación El Monte. Sevilla.

BELMONTE, J.A. Tejera A, Perera, M.A. and R. Marrero (2007): "On the orientation of preIslamic temples of North-west Africa: a reapprisal New data in Africa Proconsularis." Mediterranean Archaeology and Archaeometry 6, 3, pp. 77-85.
Lexicon topographicum urbis Romae (1993-1995): Obra coordinada por Eva Margareta Steinby y publicada por la Editorial Roma, Edicioni Quasar.

RYKWERT, Joseph (2002): La idea de ciudad. Ediciones Sígueme. Salamanca.

VITRUBIO, Marco (1993): Los Diez libros de Arquitectura. Facsímil de la edición de 1787. Imprenta Real. Madrid. Traducidos del latín y comentados por Don Joseph Ortíz y Sanz, Presbítero. Biblioteca Altafulla, Barcelona.

VITRUVIO POLIÓN, Marco Lucio (2002): Los diez libros de Arquitectura. Introducción de Delfín Rodríguez Ruiz. Versión española de José Luis Oliver Domingo. Alianza Forma. Alianza Universidad. 